\title{
Thrombosis in COVID-19: We still need to learn a lot
}

Our lives have been altered by the coronavirus disease 2019 (COVID-19) pandemic since January 2020. We are still suffering from, fighting, and learning about COVID-19. Evidence show that people with this infection, at least the ones admitted to intensive care unit, are at risk of thrombotic events. In their review, Bobescu et al. from Romania extensively evaluated the literature on thrombosis in the COVID-19 infection, from pathophysiology to therapy. This article will help to better understand the issue and manage our patients with COVID-19 and at high risk for thrombotic events.

New-onset atrial fibrillation in patients with ST-elevation myocardial infarction (STEMI) is a frequent problem that is encountered in our daily practice. It may change the prognosis of the disease and makes the anticoagulation strategy more complex, especially in patients with coronary intervention. In this issue of AJC, two articles have aimed to figure out the answers to two different questions in this group of patients, "Does new-onset atrial fibrillation in patients with acute STEMI who underwent primary percutaneous coronary intervention (PCl) change the in-hospital and post discharge prognosis?" by Arslan et al. (Turkey); and "What is the impact of kidney function on the occurrence of new-onset atrial fibrillation in patients with ST-elevation myocardial infarction" by Savic et al. (Serbia).

Gait speed is a simple-to-perform test which assesses an individual functional mobility. It is informative in patients with HFrEF as it predicts poor exercise capacity. Tanriverdi et al. from Turkey evaluated the predictors of gate speed in this population.

In their article, Türkmen and Babat offered a new score to predict the inducibility of supraventricular tachycardia in symptomatic patients without documented electrocardiography. This new score model may help clinicians in their decision for EPS, which is challenging if a patient has no documented ECG.

Zeren et al. from Turkey attempted to compare the predictive value of hemoglobin level in admission with hemoglobin level after primary $\mathrm{PCI}$ in patients with STEMI but without bleeding. In addition to well-known predictors of mortality such as age, KILLIP class, systolic blood pressure, and so forth, they claimed that post-PCI hemoglobin level was also a predictor of mortality in their research population.

Two articles in this issue focus on atherosclerosis, one of the main topics in cardiology. The first one titled, "The inhibition of miRNA-130a protects atherosclerosis through suppression of inflammation by proliferator-activated receptor $\gamma$ (PPAR $\gamma$ ) expression" by Li et al. from China is a basic science paper on the suppression of atherosclerosis. Topal et al. from Turkey focusses on the predictive role of gamma-glutamyltransferase to albumin ratio in the severity of coronary artery disease, assessed with computed tomography angiography.

This issue of AJC includes case reports, letters, and e-page originals, which we believe will be interesting and useful for our readers.

\section{Dr. Cem Barçın \\ Editor \\ Ankara-Turkey}

\author{
Address for Correspondence: Dr. Cem Barçın, Sağlık Bilimleri Üniversitesi, \\ Gülhane Tıp Fakültesi, Kardiyoloji Anabilim Dalı, Ankara-Türkiye \\ Phone: +90 5559964773 E-mail: cembarcin@yahoo.com

